\title{
Shared Death Experiences: A Multicultural Survey
}

\author{
Patrizio Tressoldi ${ }^{\circ}$, Alex A. Álvarez**, Nadir Facchin, Martina Frullanti ${ }^{\S}$, Laura Liberale ${ }^{\S}$, \\ Marcelo Saad $^{\circ}$, Yung-Jong Shiah* and Ines Testoni ${ }^{\S}$ \\ 'Science of Consciousness Research Group, Studium Patavinum, Padova University, Italy \\ ${ }^{\circ}$ Spiritist Medical Association of São Paulo, São Paulo, Brazil \\ *Graduate Institute of Counseling Psychology and Rehabilitation Counseling, \\ National Kaohsiung Normal University, Taiwan \\ **Unidad Parapsicológica de Investigación, Difusión y Enseñanza, Mexico \\ ${ }^{\S}$ End of Life, FISSPA, Padova University, Padova, Italy
}

\section{[in press on American Journal of Hospice and Palliative Medicine]}

\begin{abstract}
Background: Shared-death-experiences (SDEs) and after-death-communicationexperiences (ADCEs) are non-ordinary mental experiences related to the death of a known or unknown person.

Methods: These experiences were investigated by surveying four samples with different cultural backgrounds: Italian, Mexican, Brazilian and Taiwanese people. One-hundred-twenty-one participants reported 146 experiences of this type.

Results: Among the main characteristics of these experiences, visual, visual-auditory and feeling experiences, which comprised $74 \%$ of all experiences, were experienced both in the dream state and a normal state of consciousness. Furthermore, most of these experiences were lived before $(47.3 \%)$ or after $(39 \%)$ the death of the person in relationship with the participants.

More importantly, these experiences influenced the participants' death interpretation favoring the belief that death affects only the body, but the consciousness of the deceased persons survives in another reality and sometimes can communicate with relatives and friends still alive in this reality. No substantial differences were observed among the different subsamples.

Conclusion: As to the origin of SDEs/ADCEs, we discuss that whereas for most of them, in particular those lived after the death of a relative or a friend, we can assume hallucinatory characteristics triggered by emotional needs, for others, for example those related to unknown individuals and/or those experienced before the death of the person still in good health, it is not possible to exclude their anomalous connections and a real encounter with a deceased person.
\end{abstract}

Keywords: shared death experiences; after death communications; death; mourning; consciousness

\footnotetext{
${ }^{1}$ Corresponding author: patrizio.tressoldi@unipd.it
} 


\section{Introduction}

The main aim of this study was a multicultural comparison of the characteristics and the post-experience effects of shared-death-experiences (SDEs) and after-death-communicationexperiences (ADCEs).

The term SDEs comprise both sensory, visual, tactile, auditory or olfactory information and non-sensory experiences related to a future death, the period of dying or after the dead of a person, received often unexpectedly by his/her parents, relatives, friends and in some minor cases by individuals who are unrelated to the deceased. ADCEs are a subcategory of SDEs with identical characteristics but experienced after the death of a person. These types of experiences have also been termed Sensory and Quasi-Sensory Experiences of the Deceased (SED) by the interdisciplinary working group of the International Consortium for Hallucination Research $(\mathrm{ICHR})^{1}$.

These experiences are distinct from the so-called end-of-life and death-bed-experiences, in particular dreams and visions, which occur to both adults and children during their dying process ${ }^{2,3}$.

SDEs/ADCEs are not uncommon. Streit-Horn ${ }^{4}$ reviewed 35 surveys carried out with different USA and UK samples from 1948 to 2006 and found an average prevalence of $35 \%$ with a range from $17 \%$ to $54 \%$ in the five methodologically strongest surveys.

A recent large-scale survey of ADCEs survey conducted with English, French and Spanish people $^{4,5}$, revealed that the most common form of ADCEs was during sleep and, apart their sensorial characteristics, some participants claimed to have perceived a sense of an external presence. Furthermore, for many participants these experiences were deeply meaningful with significant positive effects in their sense of spirituality, but not religiosity and a comforting effect for their grieving condition.

Interviews in the US with 107 shared-death-experiencers (SDErs) by the Shared Cross Initiative $^{6}$, revealed similar findings: remotely sensing a death, experiencing unusual phenomena, emotions and feelings associated with the dying and long lasting positive effects on the individuals' grieving process and their interpretation of death as a transition to a new state of existence.

Given that not only can the experiences, but in particular their interpretation and post experience effects be modulated by the participants' religious, spiritual and cultural backgrounds, we thought it interesting to investigate whether such experiences are similar or different in samples with different cultural backgrounds: Taiwanese Buddhist, Mexican and Italian participants with a Catholic religious cultural background and Brazilian spiritist. Spiritism is taken as a belief system in Brazil and in other parts of the Americas. Despite having emerged in France in 1857 as a philosophical system, it had mediumistic communications as its investigative method. Although Spiritism is not a religion, it adopts the moral teachings of the Gospels as a guide to conduct.

Among the different interpretations of such experiences, Exline ${ }^{7}$, discusses three potential causes: pathological hallucinations, mentally conscious and unconscious strategies for managing grief and real communication with deceased persons.

We will discuss such interpretations in the discussion, after the presentation of our results.

\section{Methods}

\section{Ethical approval}

This study was approved by the Psychology Departments of Padova University ethical committee, prot. n. 4232 which comprised a consent form from the participants.

\section{Participants}

Each co-author, depending on his nationality, disseminated the link of the appropriate survey version to people who could have had SDEs/ADCEs, in particular people working in hospice or palliative clinics. 


\section{Survey}

Apart some personal information, the survey was composed of only five questions:

- a) "Describe as accurately as possible what you have experienced (relationship with the deceased, places, hours, experiences, etc.)";

b) "Describe as accurately as possible whether and how this experience changed your conceptions of death and life";

c) "Have you shared these experiences with others? If YES, with whom and what reactions did you get?";

d) "Do you practice or follow religious, spiritual, philosophical teachings of any kind? If yes, please indicate which ones and for how long?";

e) "Have you had other non-ordinary experiences not concomitant with death? If YES, please describe them accurately".

The English version is visible at https://forms.gle/FENUVsohJaWyyVnH9 .

Spanish, Italian, Portuguese/Brazilian, and Taiwanese versions were translated and back translated by experts in the translated and English versions.

\section{Results}

\section{General quantitative approach}

Given that our sample cannot be considered representative of a specific population (see study limitation paragraph in the Discussion section), it is not appropriate to analyze the quantitative data with inferential statistics. Consequently, we will present only descriptive statistics.

\section{$\underline{\text { Exclusion criteria }}$}

We excluded responses not related to SDEs/ADCEs, e.g., descriptions of ordinary experiences related to the death, personal reflections about the death, or reports of other persons' experiences.

\section{$\underline{\text { Valid responses }}$}

Each respondent could describe more than one experience. The number of valid responses were as follow: 26 from the Italian survey with a total of 34 experiences; 51 from the Mexican survey, which included 2 participants from Venezuela and 1 participant each from Chile, Colombia, and Spain, with a total of 59 experiences; 7 participants from the Taiwanese survey, with a total of 7 experiences (for this sample, most of respondents reported ordinal death experiences) and 37 participants from the Brazilian survey, with a total of 46 experiences. In total there were 121 respondents and 146 experiences.

For those experiences where the participants reported having had them before and during or after the death with the same person, we considered both experiences.

The full database with all responses translated into English, is freely available at https://doi.org/10.6084/m9.figshare.18865802.v1 for independent control and analyses.

\section{Classification of Experiences}

Authors NF and PT independently scored all responses according to the following variables: - time of the experience: pre, during or after the death;

- type of sensorial experience: visual, auditory, tactile, olfactory, feeling, etc.;

- state of consciousness during the experience: awake, dream, meditation, etc.;

- distance from the death: direct contact or at a distance from the dying or deceased person;

- personal relationship with the deceased person: relative, friend, acquaintance or unknown person; - change in respondents' interpretation of death as a result of the experience: death as annihilation to death as a passage (ap); death as passage to death as passage (pp); death as a passage to death as annihilation (pa); death as annihilation to death as annihilation (aa) using the terminology used by ${ }^{7}$. 
Author PT reviewed all responses and discrepancies were fixed after discussion with author NF.

\section{$\underline{\text { Participants' characteristics }}$}

Among the 114 participants who reported their gender and chronological age, 89 (78\%) were females, $24(21 \%)$ were males and $1(.08 \%)$ reported another gender.

The percentages of participants' chronological age ranges are as follows: $18-25=4.4 \%, 26-$ $35=14 \%, 36-45=23.7 \%, 46-55=22.8 \%, 56-65=27.2 \%, 66-75=6.1 \%$ and above $75=1.8 \%$.

Among the 118 participants who reported their religious-spiritual experiences, the percentages of these experiences are presented in Table 1.

Table 1: Percentages of participants' religious-spiritual experiences (RSE)

\begin{tabular}{ccc}
\hline RSE & Counts & $\begin{array}{c}\text { \% of } \\
\text { Total }\end{array}$ \\
\hline No religion & 32 & $27.1 \%$ \\
Spiritual & 20 & $16.9 \%$ \\
Catholic & 18 & $15.3 \%$ \\
Kardecist Spiritism & 16 & $13.6 \%$ \\
Meditation & 9 & $7.6 \%$ \\
Christian & 6 & $5.1 \%$ \\
Buddhism & 6 & $5.1 \%$ \\
Catholic - spiritual & 4 & $3.4 \%$ \\
Folk beliefs & 2 & $1.7 \%$ \\
Hermetic & 2 & $1.7 \%$ \\
Spiritism - Stoicism & 1 & $0.8 \%$ \\
Umbanda & 1 & $0.8 \%$ \\
Wicca & 1 & $0.8 \%$ \\
\hline
\end{tabular}

Comment

As shown in Table 1, the participants' religious-spiritual experiences are quite different. Those who reported not following any religion represent approximately a quarter $(27.1 \%)$ of the whole sample, followed by those who reported to follow a personal spiritual path (16.9\%), Catholics (15.3\%) and those following Kardecist Spiritism teachings (13.6\%), this latter category reflecting only the Brazilian sample.

\section{Other non-ordinary experiences}

Eighty-two (71.3\%) of the participants reported having had other non-ordinary experiences, ranging from precognitive dreams, out-of-body consciousness experiences, mediumship experiences, etc. 


\section{Experiences characteristics}

Deceased person: a complete description of all types of deceased persons' is presented in the Table $S 1$ in the supplementary materials. The more frequent types are these: father $(19.2 \%)$, grandmother $(12.3 \%)$, mother $(10.3 \%)$, friend $(8.2 \%)$, and grandfather $(7.5 \%)$. together, these five types of deceased persons', represent $57.5 \%$ of all types.

A more synthetic way to illustrate the types of the deceased persons' is by using the type of relationship with the participant. The percentages of these types of relationship are presented in Table 2.

Table 2: Frequencies of relationship types

\begin{tabular}{lrc}
\hline \multicolumn{1}{c}{ Relationship } & Counts & $\begin{array}{c}\text { \% of } \\
\text { Total }\end{array}$ \\
\hline relatives & 116 & $79.5 \%$ \\
acquaintances & 13 & $8.9 \%$ \\
friends & 12 & $8.2 \%$ \\
unknown persons & 4 & $2.7 \%$ \\
pet animals & 1 & $0.7 \%$ \\
\hline
\end{tabular}

Comment

From the data presented in Table 2, relatives represent the great majority of the types of deceased persons. If we add the friends' type, the overall percentage rises to $88.4 \%$, suggesting that an emotional bond with the deceased could be a strong moderator factor for the emergence of SDEs/ADCEs.

\section{$\underline{\text { Sensorial experience }}$}

The whole range of SDEs/ADCEs sensorial experiences is presented in Table S2 in the Supplementary materials. The more frequent ones are visual $(35.6 \%)$, visual-auditory $(28.1 \%)$, and feeling (sensed) $(9.6 \%)$, for a total of $73.3 \%$ of all experiences.

Typical examples of these three categories are:

BR8_1 (Visual): "In October 1996, a few hours before the death of my father, who was bedridden at home, I saw a lady who was unknown to me sitting at his bed. On this day, we had at home the presence of an older cousin who revealed after my description she is a deceased aunt whom I had never seen, not even in a photograph";

IT13_1 (visual): "I have had two such experiences. The first one was in 1988 and I dreamt that I was given three envelopes in which there was a report in each one that I was going to die of a different disease than the other two. I woke up very upset even though I knew it was only a dream. In the space of six months, three people I was very fond of died: my maternal aunt, my maternal 
grandmother and my paternal grandfather. After these events I understood the meaning of the dream."

MX2 (visual-auditory): "I dreamt that a co-worker was going to die. Days later I found out about the sick colleague in the hospital. At one point I turned to the wall and saw him expiring with a loud and clear gasp. Later we were informed of his death. At night I heard noises in my kitchen and as I approached in the dark, I could hear him standing there. I spoke to him and said goodbye".

MX32 (visual-auditory): "When my mother passed away after going to the cemetery, I saw her saying goodbye to me sitting at her kitchen window as she always did, with her smile on her face"

IT16_1 (feeling): "The first experience was in 2004 (I was attending the primary school) and I was in my great-grandmother's room at the nursing home with my grandfather and I felt these unpleasant sensations coming from my great-grandmother and after a few months she died."

IT16_3 (feeling): "The third one was in 2014. I was visiting a family friend who was not well physically and I felt negative feelings. After 2/3 months this person also died".

We suggest reading all these experiences in the database because they offer a rich variety of SDEs/ADCEs first-person experiences.

There were no substantial differences among the three different Italian, Mexican and Brazilian subsamples.

$\underline{\text { State of consciousness }}$

Participants' states of consciousness during the SDEs/ADCEs are presented in Table 3.

Table 3: Frequencies of the states of Consciousness

\begin{tabular}{lcc}
\hline & Counts & \% of Total \\
\hline dream & 74 & $50.7 \%$ \\
normal & 69 & $47.3 \%$ \\
meditation & 2 & $1.4 \%$ \\
altered & 1 & $0.7 \%$ \\
\hline
\end{tabular}

Comment

It is interesting that the frequency of SDEs/ADCEs in the dream and the normal (awake) states of consciousness is approximately similar. Together they represent $98 \%$ of all experiences.

Here are some examples of the experiences in these two states of consciousness.

IT11 (dream): “The night after my father's death, I dreamt that I was at my grandmother's house and that on the way out of the house, I met all my relatives, but instead of their faces, I saw my father talking to me. I accompanied him to the exit door and at that moment he stopped me and said goodbye, telling me that we would see each other again one day". 
MX18_2 (dream): "I also have a very similar experience with my husband's grandmother, very dear to me. I dream of her very often, and sometimes I can even touch her. At the beginning the experience was very impressive, but now I see it with pleasure and as something natural".

MX12 (normal):" My wife passed away, six months ago, but I was with her for a whole week, taking care of her during her transition. A day before she passed away, I had a feeling of despondency in my chest, as if something had broken. I think it was my heart literally breaking and it lasted for something like three or four minutes that sensation. The next day he died, but I still feel that sensation near the bed where we used to sleep and until I don't fall asleep, it disappears".

IT24 (normal): "My father had been dead for five days. I bought a phone and suddenly I got a message on my answering machine. I listened to it and I was shocked and scared. The voice message was from my father and he said "it's daddy please don't be scared my daughter. I'm not here anymore but please don't worry you're not alone and you'll never be alone, I love you, now I have to go". I wanted someone to listen to the message the next day, but a message told me that the voice message had deleted itself. I don't understand how this could have happened to me".

\section{$\underline{\text { Sensorial experiences and state of consciousness }}$}

The differences among the more frequent types of sensorial experiences in the two main states of consciousness are presented in Figure 1.

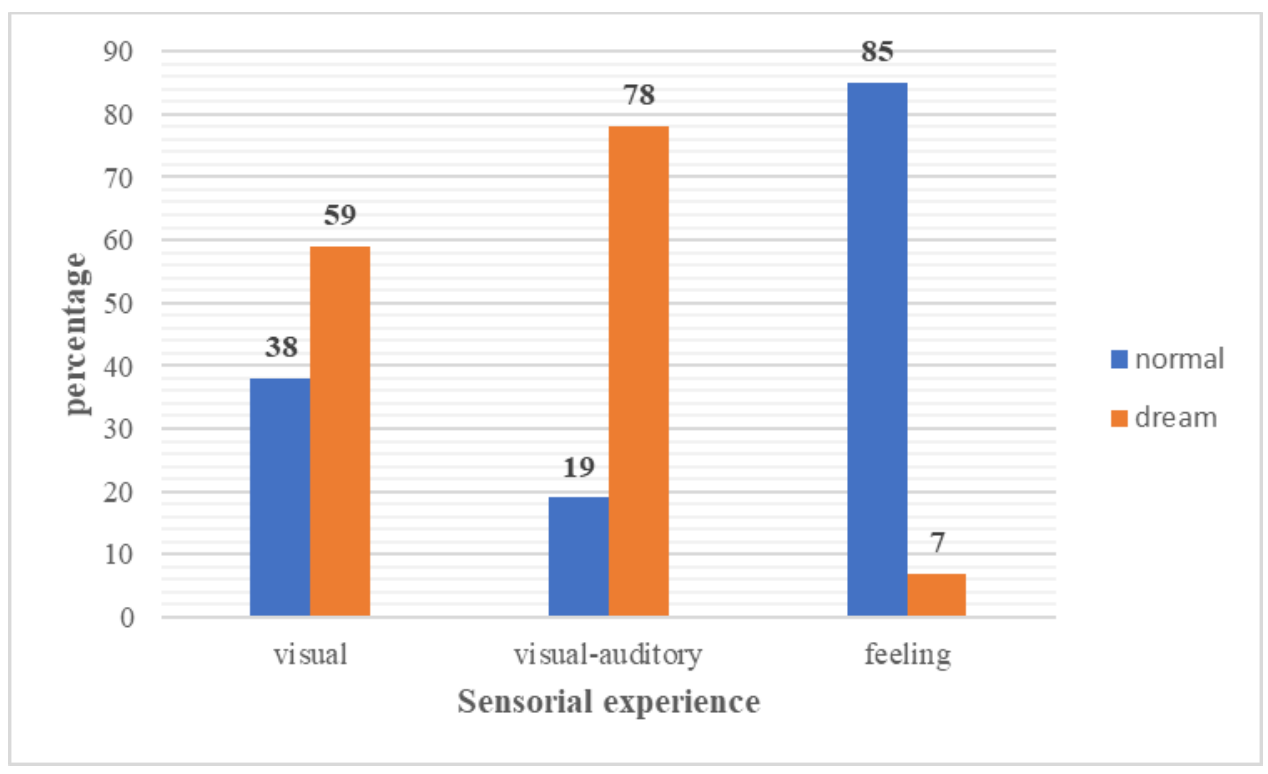

Figure 1: Percentage of the types of sensorial experiences in the normal and dream state of consciousness.

Comment

Whereas the frequency of the sensorial experiences with only visual content is almost similar in the dream and the normal state of consciousness, those experiences with visual and auditory contents are more frequent in the dream state and those with sensorial feelings in the normal one. We will comment on these differences in the general discussion. 
$\underline{\text { Time of SDEs/ADCEs and distance from the deceased person }}$

The time when participants lived their experiences, is reported in Table 4. Most of the experiences, $88.4 \%$ were lived at a distance from the deceased or dying person.

Table 4: Time when participants lived their experiences

\begin{tabular}{lrr}
\hline & Counts & \% of Total \\
\hline before death & 69 & $47.3 \%$ \\
after death & 57 & $39.0 \%$ \\
during death & 20 & $13.7 \%$ \\
\hline
\end{tabular}

Effects of SDEs/ADCEs on the participants' interpretation of death

Sixty-nine participants reported on how their SDE/ADCE influenced their interpretation of death. Of the participants, $8.6 \%$ maintained their interpretation that death is the end not only of the body, but also of consciousness. For example, BR11_1 stated: "The feeling I have is that death warns me...I don't like it...I'm afraid".

For the $47.8 \%$ of the participants, their experience reinforced an interpretation that the death is only related to the body, but that the consciousness of the deceased person continues in another reality. For example, BR7_1 explained: "I have always believed in the relationship between spirit and flesh, so these experiences only strengthened my belief and my knowledge".

Differently, for $43.4 \%$ of participants, their experience changed their interpretation of death, from that of total annihilation to the annihilation of only the body and the survival of human consciousness in another reality. This was illustrated by BR19_1 who said: "The experiences with my father and my aunt were part of the construction of my spirituality. The experience with my sister helped me to cope with grief and changed my way of looking at life as a whole".

In Figure 2, we present the percentages of participants' interpretation of death before and after their SDEs/ADCEs, separately for those with and without religious/spiritual experiences. 


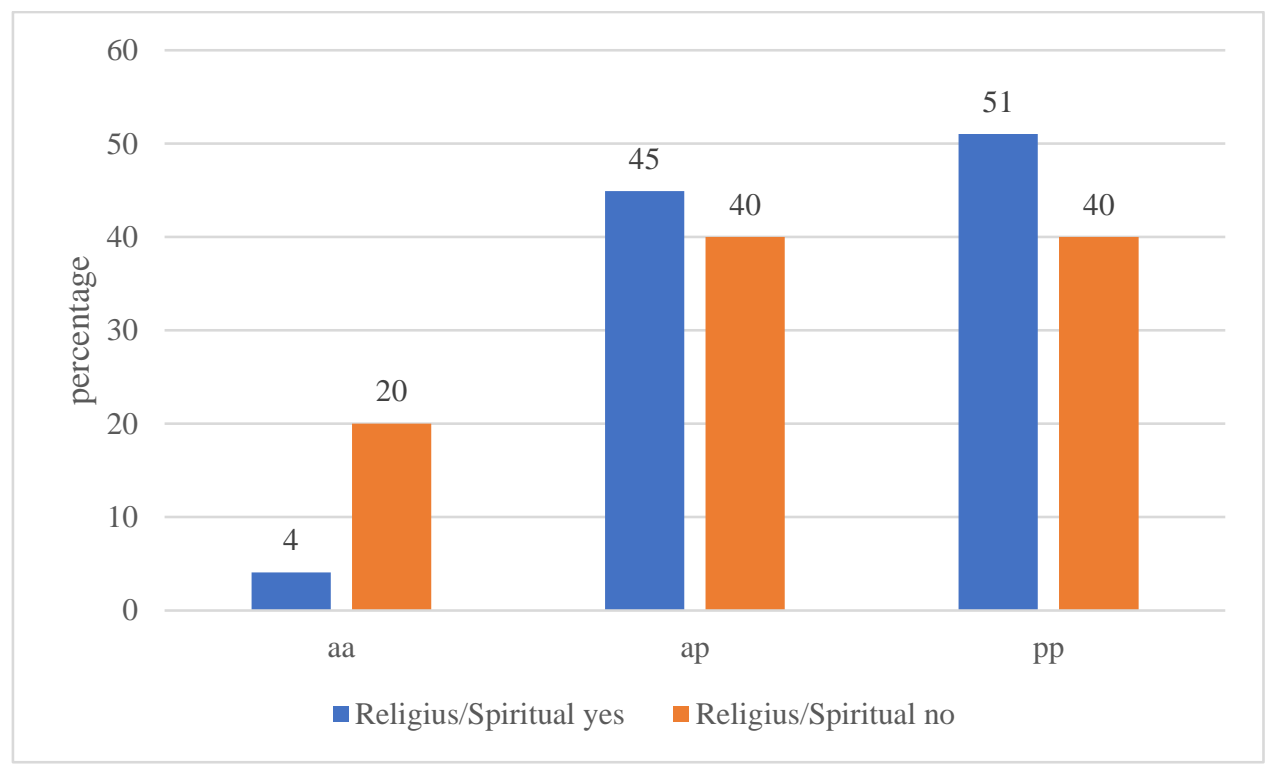

Figure 2: Percentages of participants' death interpretation before and after their SDEs/ADCEs separately for those with and without religious/spiritual experiences. $(\mathrm{aa}=$ annihilation before and after; $\mathrm{pp}=$ passage before and after; ap = annihilation before and passage after)

\section{Comment}

Considering that participants who declared not following religious/spiritual practices comprise only the $27 \%$ of the whole sample, religiosity/spirituality seems to have slightly influenced the change from the interpretation of death as total annihilation to a passage to another reality and to have reinforced this last interpretation for those who already held it. In contrast, the lack of religious/spiritual experiences reinforced the interpretation of the death as total annihilation for those who already held that view.

There were no substantial differences among the Italian, Mexican, and Brazilian subsamples.

\section{Discussion}

\section{$\underline{\text { Study limitation }}$}

As anticipated, our study as well as all similar ones related to this topic, cannot be considered representative of a specific population, e.g., nationality, spiritual/religious believes, gender, because participants were randomly sampled and were self-selected. However, the comparison of our findings with those observed in other studies is useful for testing the generalizability of such a type of experiences in the general population.

\section{$\underline{\text { Participants' characteristics }}$}

Similar to Elsaesser et al. ${ }^{4}$, Penberthy et al. ${ }^{9}$, and the Shared Cross Initiative ${ }^{6}$, most of our participants were women. Does this finding suggest that women are more prone to SDEs/ADCEs, because they express stronger emotional bonds with their deceased? Or could their prevalence simply be due to the fact that women are more open to talking about their non-ordinary experiences 
compared to males? Only the recruitment of a representative sample of men and women could offer a clearer response to this gender difference.

Furthermore, the high percentages, $71 \%$, of participants declaring to have had other nonordinary experiences, suggest that in future studies, their personality characteristics should be studied to explore if some of them, like, fantasy-proneness, schizotypy, etc., could favor such a type of experiences.

\section{$\underline{\text { SDEs/ADCEs characteristics }}$}

The prevalence of visual and visual-auditory experiences observed in our study is similar to those reported by Elsaesser et al. ${ }^{4}$, Penberthy et al. ${ }^{9}$, and the Shared Cross Initiative ${ }^{6}$. The main difference was related to tactile experiences which were reported as more frequent in the above cited studies than in our one.

Similar to the Shared Cross Initiative ${ }^{6}$, and Elsaesser et al. ${ }^{4}$, studies, SDEs/ADCs were lived both in a dream state and in a normal state of consciousness and at a distance from the dead or dying person.

Given that no previous study has reported on the differences between the sensorial experiences in the dream state and the normal state of consciousness, those we found as presented in Figure 2, can only be provisionally interpreted. We postulate that in the normal state of consciousness it is more difficult to detect visual, auditory and in particular oral language information. given the enhanced mental noise in this state, favoring the detection of feeling/emotional information.

\section{Effects of SDEs/ADCEs on participants' interpretation of death}

The impact of these experiences on the belief that death is not the end of human existence, but only that of the human body, whereas consciousness continues to exist in another reality, which we observed in our study, is similar to that observed by the Penberthy et al. ${ }^{9}$. It is very likely that the participants' religiosity/spirituality beliefs very probably influence such interpretation.

\section{$\underline{\text { Hallucinations or real encounters? }}$}

As anticipated and discussed in the introduction, such experiences could derive from mentally conscious and unconscious bereavement hallucinations as a way of managing grief and/or the need for a continuing and a real communication with deceased persons ${ }^{1,10,11}$ both in a clinical or non-clinical condition of grief disorders.

Considering the effects on the participants' death interpretation of death, these experiences were considered as real communication with the deceased person even when lived in a dream state. However, these effects are not sufficient to exclude the possibility that these experiences may derive from a strong need to continue the relational bond with the deceased and to relieve the respondents' sorrow over that person's death.

However, such an interpretation does not hold when such experiences are related to mere acquaintances or unknown persons which was the case for $11.6 \%$ of the whole sample. See for example IT2: "I did not know the deceased. One morning in my dream this person came smiling to me and told me to tell his brother (whom I knew even if only marginally) that he was finally well and not to worry! In the morning I called the person on the phone and told him what had happened 
(also because I didn't know he had a brother and it seemed strange to me, but the dream was so vivid that it gave me a strange feeling), whereupon he hung up the phone and told me he would see me later! When he came, he explained that he had a brother with cancer who had died during the night!"

and IT26_1: "The first time I dreamt of a person who had just died (without my knowledge) I was in my early twenties. I had simply seen in the dream an ex-boyfriend of my mother-in-law's, a doctor I knew very little about. I told my husband that I had seen him in my dream and we were very surprised. After a few hours my mother called us to tell that he had died during the night. This upset me a lot, also because it was a person I didn't know very well."

Furthermore, the hallucination hypothesis does not hold for the experiences related to persons still leaving and in good health. See for example IT5_2: "I had just turned 19 and the previous year I had lost a friend in a car accident. She appeared to me in a dream and said we were fine, referring also to the person next to her. I recognized the person with his back to me, another friend of ours. The place was dark, black, but I could see them very well as if they were lit by lamps. I woke up immediately afterwards, I thought I was mourning, except that the person on the back died two months after this dream, also in a car accident. I find it very difficult to believe that this was a coincidence."

MX2: "I dreamt that a co-worker was going to die. Days later I found out about the sick colleague in the hospital. At one point, I turned to the wall and saw him expiring with a loud and clear gasp. Later we were informed of his death. At night I heard noises in my kitchen and as I approached in the dark, I could hear him standing there. I spoke to him and said goodbye".

\section{$\underline{\text { Final comments }}$}

SDEs/ADCEs are not uncommon in the general population and often have positive effects on the experiencers ${ }^{8,12}$. As to their origin, we think that whereas for most of them, we can assume emotional needs as a sufficient cause, see for example the literature related to the continuing bond in bereavement ${ }^{13,14}$, for others, the cause is more compatible with a real non-ordinary mental encounter with a dying or deceased person.

More convincing proofs are necessary to support the hypothesis of the survival of human consciousness and the possibility to engage in real encounters with deceased persons, but we think that a correct scientific approach is not to dismiss this hypothesis a priori as impossible.

We conclude this paper by referring to one of the most intriguing experiences, that one reported by MX40 (see the Supplementary materials). This particular experience supports our recommendation to be open to the possibility of a real continuing bond with deceased persons. 


\section{Authors Contribution}

PT: Conceptualization; Methodology; Formal analyses; Data Curation; Writing original draft; Writing - Review \& Editing; Supervision.

AA, MS, NF, YJS: Data Curation; Writing original draft; Writing - Review \& Editing; Supervision.

LB; MF; IT: Writing - Review \& Editing; Supervision.

\section{Acknowledgments}

We thank all participants of this survey for their interest in sharing with us their non-ordinary experiences.

Proof Reading Service revised English 


\section{References}

1. Kamp KS, Steffen EM, Alderson-Day B, et al. Sensory and Quasi-Sensory Experiences of the Deceased in Bereavement: An Interdisciplinary and Integrative Review. Schizophr Bull. 2020;46(6):1367-1381. doi:10.1093/SCHBUL/SBAA113

2. Renz M, Reichmuth O, Bueche D, et al. Fear, Pain, Denial, and Spiritual Experiences in Dying Processes. Am J Hosp Palliat Med. 2018;35(3). doi:10.1177/1049909117725271

3. Depner RM, Grant PC, Byrwa DJ, et al. Expanding the Understanding of Content of End-ofLife Dreams and Visions: A Consensual Qualitative Research Analysis. Palliat Med Reports. 2020;1(1). doi:10.1089/pmr.2020.0037

4. Streit-Horn J. A systematic review of research on after-death communication (ADC). 2011.

5. Shared Cross Initiative. Shared Death Experiences: A Little-Known Type of End-of-Life Phenomena Reported by Caregivers and Loved Ones. Am J Hosp Palliat Med. 2021;38(12):1479-1487. doi:10.1177/10499091211000045

6. Exline JJ. Psychopathology, normal psychological processes, or supernatural encounters? Three ways to frame reports of after-death communication. Spiritual Clin Pract. 2021;8(3):164-176. doi:10.1037/SCP0000245

7. Testoni I, Ancona D, Ronconi L. The ontological representation of death: A scale to measure the idea of annihilation versus passage. Omega (United States). 2015;71(1). doi:10.1177/0030222814568289

8. Elsaesser E, Roe CA, Cooper CE, Lorimer D. The phenomenology and impact of hallucinations concerning the deceased. BJPsych Open. 2021;7(5):e148. doi:10.1192/BJO.2021.960

9. Penberthy JK, Pehlivanova M, Kalelioglu T, et al. Factors Moderating the Impact of After Death Communications on Beliefs and Spirituality: Omega - J Death Dying. July 2021. doi:10.1177/00302228211029160

10. Mäkikomsi M, Terkamo-Moisio A, Kaunonen M, Aho AL. Unexplained experiences in the context of bereavement-qualitative analysis. Mortality. 2021. doi:10.1080/13576275.2021.1991903

11. Castelnovo A, Cavallotti S, Gambini O, D’Agostino A. Post-bereavement hallucinatory experiences: A critical overview of population and clinical studies. J Affect Disord. 2015;186. doi:10.1016/j.jad.2015.07.032

12. Kamp KS, Steffen EM, Moskowitz A, Spindler H. Prevalence and Phenomenology of Sensory Experiences of a Deceased Spouse: A Survey of Bereaved Older Adults. Omega (United States). 2021. doi:10.1177/00302228211016224

13. Tidwell BL, Larson ED, Bentley JA. Attachment Security and Continuing Bonds: The Mediating Role of Meaning-Made in Bereavement. J Loss Trauma. 2021;26(2). doi:10.1080/15325024.2020.1753389

14. Klass D [Ed], Steffen EM [Ed]. Continuing bonds in bereavement: New directions for research and practice. Contin Bond Bereave New Dir Res Pract. 2018;(December). 
Supplementary Materials

Table S1: Counts and frequencies of the identity of the deceased persons

\begin{tabular}{|c|c|c|}
\hline Deceased & Counts & $\%$ of Total \\
\hline father & 28 & $19.2 \%$ \\
\hline grandmother & 18 & $12.3 \%$ \\
\hline mother & 15 & $10.3 \%$ \\
\hline friend & 12 & $8.2 \%$ \\
\hline grandfather & 11 & $7.5 \%$ \\
\hline aunt & 8 & $5.5 \%$ \\
\hline uncle & 5 & $3.4 \%$ \\
\hline brother & 4 & $2.7 \%$ \\
\hline father-in-law & 4 & $2.7 \%$ \\
\hline sister & 4 & $2.7 \%$ \\
\hline great-grandmother & 3 & $2.1 \%$ \\
\hline husband & 3 & $2.1 \%$ \\
\hline known person & 2 & $1.4 \%$ \\
\hline mother-in-law & 2 & $1.4 \%$ \\
\hline nephew & 2 & $1.4 \%$ \\
\hline brother & 1 & $0.7 \%$ \\
\hline brother-in-law & 1 & $0.7 \%$ \\
\hline Husband's grandmother & 1 & $0.7 \%$ \\
\hline adolescent & 1 & $0.7 \%$ \\
\hline aged men & 1 & $0.7 \%$ \\
\hline brother-in-law & 1 & $0.7 \%$ \\
\hline classmate & 1 & $0.7 \%$ \\
\hline co-worker & 1 & $0.7 \%$ \\
\hline cousin & 1 & $0.7 \%$ \\
\hline cousin's husband & 1 & $0.7 \%$ \\
\hline daughter's boyfriend & 1 & $0.7 \%$ \\
\hline doughter & 1 & $0.7 \%$ \\
\hline family members & 1 & $0.7 \%$ \\
\hline father's boyfriend & 1 & $0.7 \%$ \\
\hline friend's father & 1 & $0.7 \%$ \\
\hline godfather & 1 & $0.7 \%$ \\
\hline
\end{tabular}




\begin{tabular}{lcc}
\hline \multicolumn{1}{c}{ Deceased } & Counts & \% of Total \\
\hline great-aunt & 1 & $0.7 \%$ \\
headmistress & 1 & $0.7 \%$ \\
mother-in-law ex-boyfriend & 1 & $0.7 \%$ \\
pet animal & 1 & $0.7 \%$ \\
roommate & 1 & $0.7 \%$ \\
son & 1 & $0.7 \%$ \\
stepfather & 1 & $0.7 \%$ \\
unknown person & 1 & $0.7 \%$ \\
wife & 1 & $0.7 \%$ \\
\hline
\end{tabular}

Table S2: Counts and frequencies of SDE/ADC sensorial experiences

\begin{tabular}{lcc}
\hline Sensorial experience & Counts & \% of Total \\
\hline visual & 52 & $35.6 \%$ \\
visual - auditory & 41 & $28.1 \%$ \\
Feeling (sensed presence) & 14 & $9.6 \%$ \\
auditory & 9 & $6.2 \%$ \\
visual - tactile & 8 & $5.5 \%$ \\
tactile & 5 & $3.4 \%$ \\
visual - auditory - tactile & 4 & $2.7 \%$ \\
visual - smell & 3 & $2.1 \%$ \\
telepathic & 2 & $1.4 \%$ \\
energetic & 1 & $0.7 \%$ \\
feeling - tactile & 1 & $0.7 \%$ \\
smell & 1 & $0.7 \%$ \\
smell - visual & 1 & $0.7 \%$ \\
tactile - emotions & 1 & $0.7 \%$ \\
visual - auditory - bad feeling & 1 & $0.7 \%$ \\
visual - auditory - smell & 1 & $0.7 \%$ \\
visual - feeling & 1 & $0.7 \%$ \\
\hline
\end{tabular}




\section{A special experience}

MX40: "I had a meeting with a friend who had died three and a half years earlier of fulminant cancer. It was around 11:00 a.m. a few blocks from the house where she lived. I was walking home when I suddenly heard a "pst pst pst". I continued straight ahead without paying attention and again hearing the same thing. I turned around and saw my friend smiling at me and extending her hands towards me saying in a loud voice "Hi, what's up? Hello, don't you want to greet me? You don't recognize me anymore or what?". At the moment it was a shock. I observed her carefully from head to toe (she looked extraordinarily young and beautiful) and I noticed that the other people around her also saw her, as they turned around (they did not pass through her body as they passed). A little more focused, I approached her, but still doubting why she was there... I remembered thinking that perhaps I had mistaken her death for that of someone else.... In my mind I told her that I had been informed that she had passed away and then she answered me with an affirmative nod of her head (as if she had heard me) only then I extended my hand to greet her and kissed her cheek.

I noticed her beautiful skin (only her skin folds were not visible), good temperature and I told her that I never judged her. She did something strange...

She said: "I know", she stood at attention and leaned towards me and told me that "It was an honor to talk to me". I also acted in the same way... I felt very strange, then I started to ask her questions such as the current state of her children and she was giving me reference of each one with extreme precision. I then asked about her husband. About him she told me he was a wonderful Being and that with what he had done in her absence he had already earned heaven. ... Then, a bit more nervous, I began to ask her what his state of mind was. I began to ask what her state was, how she was feeling... then she said: "We can't complain, they cure us there". It's similar, but not the same" and she began to tell me that "It is very important not to judge anyone and even ourselves" that "if we keep at it we could go straight to a place and avoid the place where she was. While she was talking to me, she was signaling me with her eyes to look over my left shoulder. I did turn around several times, but I didn't see anything strange... she looked very smiling, but I did miss the phrase "Don't look at me". I was surprised by the phrase "We can't complain" as if she meant that there was a more desirable place or as she didn't feel completely free... Soon we said goodbye. I told her that I was late to get home and she smiled at me and told me that I had to go home.

She smiled at me and told me that her leave was about to expire as well... She stood up straight again, leaned towards me and said again "It's an honor to talk to you" I did the same again and told her that the honor was all mine... and we went on our way... I didn't turn to see where or how he was leaving... Three days later, I went to my parents' house and told them about the meeting... they thought it was very strange, they invited me for a glass of water (they noticed that I was excited) and made me sit down... My father said to me, calm down and tell me again who you found. I told them again that it was that friend (I reserve her name out of respect for her cycle) and then my father looked in his mobile phone for a photo that he had taken of her grave the day of her burial.... I felt between sad and happy... very strange... then my mum told me that just that day that I found that friend, her husband had passed away... I imagine that when she was pointing at me with her eyes maybe her husband was perhaps the one on my left side... In honor of the truth and with respect to your intelligence, I confirm that what I have written here is all true." 